\title{
Taxonomy of Digital Platforms: A Business Model Perspective
}

\author{
Nicola Staub \\ University of St.Gallen \\ nicola.staub@unisg.ch
}

\author{
Kazem Haki \\ University of St.Gallen \\ kazem.haki@unisg.ch
}

\author{
Stephan Aier \\ University of St.Gallen \\ stephan.aier@unisg.ch
}

\author{
Robert Winter \\ University of St.Gallen \\ robert.winter@unisg.ch
}

\begin{abstract}
Digital platforms (DPs) - technical core artifacts augmented by peripheral third-party complementary resources - facilitate the interaction and collaboration of different actors through highlyefficient resource matching. As DPs differ significantly in their configurations and applications, it is important from both a descriptive and a design perspective to define classes of DPs. As an intentionally designed artifact, every classification pursues a certain purpose. In this research, the purpose is to classify DPs from a business model perspective, i.e. to identify DP clusters that each share a similar business model type. We follow Nickerson et al.'s (2013) method for taxonomy development. By validating the conceptually derived design dimensions with ten DP cases, we identify platform structure and platform participants as the major clustering constituent characteristics. Building on the proposed taxonomy, we derive four DP archetypes that follow distinct design configurations, namely business innovation platforms, consumer innovation platforms, business exchange platforms and consumer exchange platforms.
\end{abstract}

\section{Introduction}

Around twenty years ago, when large internet companies from the Silicon Valley built the first digital platform (DP) companies based on technological advances, it was not foreseeable what a success story they would become [1]. These highly scalable organizations facilitate interaction and collaboration between different user groups through highly efficient match making [2]. Companies are constantly moving from a product-based competition strategy towards a platform-based competition strategy, which has been rapidly increasing the number of DPs on the market $[1,3]$. Since DPs are often part of business ecosystems, they allow their owners to harness the power of external developers that provide complementary technologies, products or services, which often leads to an increase in innovation [2, 4]. DPs are omnipresent in many industries but differ in their configurations, as illustrated by the examples of operating system platforms (e.g. Android, iOS), payment platforms (e.g. PayPal, Apple Pay) or peer-to-peer platforms (e.g. Uber, Airbnb).

The demonstrated variety in configurations and applications of DPs, which in turn leads to a lack of conceptual clarity regarding the notion of DP [5], calls for a classification of platform types from different vantage points [3]. Against this backdrop, we argue that platform designers and managers, aiming to commence a platform-based business or to turn their current business to a platform ecosystem, lack guidance on their design decisions regarding the DP business model. DP design guidance from a business model perspective is needed because the selection of an appropriate business model to sustainably run a DP entails conflicting design decisions due to the integration of a plethora of loosely-coupled business actors into the platform ecosystem [6-8].

Therefore, we seek to develop a DP taxonomy from a business model perspective. Taxonomies are purposefully designed artifacts that are important for both research and practice because the classification of objects helps researchers and practitioners understand and analyze complex domains [9]. Analyzing and classifying DPs based on their business models provides us with dimensions and characteristics that help distinguish different platforms and help us understand patterns and clarify design decisions related to the DP business model. Therefore, we seek to answer the following research question: Which business model dimensions are most relevant to distinguish various types of digital platforms?

As a first step towards answering the research question, we provide an overview of the dominant discourses in DP and business ecosystem literature and apply the business model approach to the study of DPs. Then we specify the utility of DP design guidance and derive taxonomy design requirements. Subsequently, we apply Nickerson et al.'s (2013) 
step-by-step procedure to develop our taxonomy [9]. As part of this process, we first identify important design dimensions and characteristics of DPs from the literature. We then use these dimensions to analyze ten DP cases in order to provide the empirical insights that define the final dimensions of our taxonomy. Based on the proposed taxonomy, we derive four distinct archetypes of DPs that follow different design configurations.

\section{Research Background}

In the following subsections we provide an overview of the dominant discourses in DP and business ecosystem literature and apply the business model approach to the study of DPs.

\subsection{Digital Platforms and Business Ecosystems}

Digital platforms have been discussed from economic, technological and information systems perspectives [10].

First, the economic perspective studies two- or multi-sided markets that facilitate interactions between their sides [11]. Ideally, network effects emerge when an increasing number of users on one side increase the value for the other side [12]. Marketplaces, also known as transaction platforms, are one important subclass of multi-sided platforms that promote winner-take-it-all markets $[1,11]$.

Second, the technological perspective considers DPs as purpose-oriented digital technologies that consist of a modular architecture with three major components: the complements (usually apps or addons) that exist in a high variety and often change over time, the relatively stable core components (i.e. the platform itself as an extensible codebase) and the interfaces that allow these two parts to operate as one system (e.g. application programming interfaces or software development kits) [13-15].

Third, the information systems perspective refers to both the economic and the technological perspectives and takes technical as well as social aspects into consideration in so-called sociotechnical systems [5]. Such platform organizations are conceptualized as follows: (a) they coordinate business actors that can both innovate and compete, (b) harness economies of scope in supply and/or demand and (c) consist of a modular technological architecture with a core and a periphery [10].

DPs are considered as the center of gravity of their respective business ecosystem. Considering the platform-enabled ecosystem is of relevance when investigating platforms' business models.

Borrowed from biology, the ecosystem concept has been discussed in three general research streams: business ecosystem, innovation ecosystem or platform ecosystem perspective [4].

First, business ecosystems create an economic community of interacting organizations and individuals that create value for customers. Such organizations and individuals co-evolve their capabilities and roles over time and are themselves aligned through set out directions by one or more central companies [16].

Second, innovation ecosystems focus on focal innovation and the collaborative arrangements of usually economic actors that combine their individual offerings into a coherent and customer-centric solution $[17,18]$.

Third, the platform ecosystem takes a hub and spoke form with a central platform (i.e. hub) and peripheral firms that facilitate complements (i.e. spokes) and are connected via boundary resources [4]. This perspective particularly focuses on the relationship of the platform owner (e.g. sponsor, provider) and the complementors (e.g. external developers) that are governed by the implementation of rules and standards [15].

For our endeavor of designing a taxonomy, inspired by Gawer (2014) and Jacobides et al. (2018), we define DPs as software-based systems that a) consist of a modular technological architecture, b) coordinate external actors that innovate and/or compete and c) can function as a central hub of an ecosystem, in which peripheral firms or individuals facilitate complements and are connected via boundary resources.

\subsection{Business Models}

The notion of business model emphasizes on a holistic, boundary spanning perspective to describe how a firm operates [19]. A business model "describes the design or architecture of the value creation, delivery and capture mechanisms [a firm] employs" [8]. For our taxonomy development, we apply the well-established business model navigator [20] with its four categories: value proposition, target customer, revenue model and value chain. In line with the purpose of our taxonomy to organize design dimensions regarding a DP's business model into a coherent organizing structure, this approach allows us to capture relevant aspects of a business model in a limited but distinct number of dimensions with 
associated characteristics, thereby facilitating the identification of archetypes.

\section{Methodology}

In this section, we describe the step-by-step procedure that we apply for our taxonomy development. From a Design Science Research (DSR) perspective, a taxonomy is a designed artifact of type model [21]. While generally following the standard DSR research process [22], we instantiate it by following Nickerson et al.'s (2013) wellstructured method for taxonomy development that has been frequently used in information systems research [e.g. 23, 24].

\subsection{Definition of Meta-characteristics}

The purpose of our taxonomy is to organize the various instances and conceptualizations of DPs into a coherent organizing structure from a business model perspective. Therefore, we specify the overarching business model configurations as the meta-characteristic that will serve as the basis for the choice of design dimensions during our taxonomy development process.

\subsection{Determination of Satisfactory Conditions}

We apply subjective and objective ending conditions that must be met in order for the taxonomy to be accepted. Objectively, the taxonomy must contain dimensions that are mutually exclusive and collectively exhaustive. The taxonomy must also comprise dimensions that cover the main aspects of a business model (i.e. value proposition, target customer, revenue model and value chain) according to the definition provided in the previous chapter. Subjectively, the taxonomy must be concise, extendible, robust, explanatory and comprehensive.

\subsection{Selection of Approach}

Nickerson et al. (2013) provide two different approaches, the empirical-to-conceptual (E2C) and the conceptual-to-empirical $(\mathrm{C} 2 \mathrm{E})$. We apply the $\mathrm{C} 2 \mathrm{E}$ approach because we have identified important dimensions and associated characteristics in DP literature from previous research.

\subsection{Conceptualization of Dimensions and Characteristics}

As input for our taxonomy development process, we use literature on DPs and business ecosystems to identify suitable design dimensions and related characteristics to classify DPs from a business model perspective. Subsequently, we structure the dimensions according to an established business model framework [20] and its four categories: value proposition, target customer, revenue model and value chain. Table 1 depicts our design dimension candidates and possible characteristics for each dimension (see also Table 3 in the appendix for an overview of the descriptions and references used).

Table 1. Design dimension candidates and characteristics of digital platforms

\begin{tabular}{|c|c|c|c|c|c|c|}
\hline Category & Design dimension & \multicolumn{5}{|c|}{ Characteristics } \\
\hline \multirow{6}{*}{$\begin{array}{l}\text { Value } \\
\text { Proposition }\end{array}$} & Key activity & Data services & Partner & gement & & nunity building \\
\hline & Key value proposition & \multicolumn{2}{|c|}{ Efficiency } & \multicolumn{3}{|c|}{ Emotional/social value } \\
\hline & Platform structure & \multicolumn{2}{|c|}{ Exchange platform } & \multicolumn{3}{|c|}{ Innovation platform } \\
\hline & Interface & Web-based & \multicolumn{2}{|c|}{ Mobile app } & & Both \\
\hline & Interaction content & Product & \multicolumn{2}{|c|}{ Service } & & Both \\
\hline & Interaction type & Digital & \multicolumn{2}{|c|}{ Offline } & & Both \\
\hline Target Customer & Platform participants & \multicolumn{2}{|c|}{ Business } & \multicolumn{3}{|c|}{ Consumer } \\
\hline \multirow[t]{3}{*}{ Revenue Model } & Key revenue stream & Commissions & Subscriptions & \multicolumn{2}{|c|}{ Advertising } & Service sales \\
\hline & Price discovery & \multicolumn{2}{|c|}{ Orchestrator } & \multicolumn{3}{|c|}{ Market pricing } \\
\hline & Price discrimination & Feature & Location & Quan & & None \\
\hline \multirow[t]{6}{*}{ Value Chain } & Coordination & \multicolumn{2}{|c|}{ Hierarchy } & \multicolumn{3}{|c|}{ Market } \\
\hline & Accessibility & Opened & $\mathrm{Re}$ & & & Closed \\
\hline & Interaction mode & \multicolumn{2}{|c|}{ Collaborative } & \multicolumn{3}{|c|}{ Competitive } \\
\hline & Direct network effects & Strong & \multicolumn{2}{|c|}{ Moderate } & & None \\
\hline & Economies of scale & Strong & \multicolumn{2}{|c|}{ Moderate } & & None \\
\hline & Integration & Horizontal & \multicolumn{2}{|c|}{ Vertical } & & None \\
\hline
\end{tabular}




\subsection{Examination of Cases for Dimensions and Characteristics}

To verify the appropriateness of the design dimension candidates and characteristics, we use them to analyze ten cases. Appropriateness hereby refers to their ability to distinguish different DP types.

To this end, we select ten cases from the real estate industry, as an exemplary industry that has been significantly impacted by DPs. Selecting the cases from a single industry enables us to achieve a relatively larger diversification of business models, which ultimately facilitates the derivation of archetypes. Within this particular industry, cases are chosen from the PropTech Yearbook 2018 [25], an established database that contains a total of 368 companies that are considered to be promising in their field. We apply four specific exclusion criteria. First, the yearbook is screened with the term platform (and Plattform, the German term) which leaves 78 potential cases. Second, the cases must be verified as DPs according to the definition provided in the research background, which leaves 37 cases. Third, a sufficient level of secondary data must be available. We only use secondary data that is publicly accessible via the Internet. Fourth, crucial industry sectors (i.e. real estate search, real estate financing, construction management, property management, asset management and investment management) must be covered which reduces the number of cases to ten.

For every case, we identify the most suitable characteristic for each dimension (see Table 4 in the appendix for an overview of all cases and their focus characteristics for each dimension). For instance, regarding the design dimension platform structure, Flatfox' business model includes both aspects of the characteristic exchange platform (e.g. its consumeroriented housing portal) and the characteristic innovation platform (e.g. its aim to connect different actors along the real estate life cycle to facilitate their collaboration and to increase overall end consumer value). We classify Flatfox as an innovation platform for the design dimension platform structure due to the fact that elements of the innovation platform characteristic appear to be most important to the firm's ability to generate revenue.

\subsection{Definition of Key Dimensions of the Taxonomy}

To classify DPs from a business model perspective, the next step is to choose the major distinguishing dimensions (i.e. key dimensions) from the ones that we identified as relevant in the previous step. To achieve this, we aim to select those key business model dimensions that are useful to classify the cases and also influential on other dimensions. For instance, regarding the dimension price discovery all cases except immorocks are classified as platform orchestrator. This distribution could be different when other cases are selected, but it can be argued that the dimension is useful to classify cases, as different characteristics were found. However, we argue that this dimension is not influential on other dimensions, as it is the only dimension where immorocks has a different characteristic (compared to all other cases). Therefore, immorocks is a special case when it comes to price discovery. An example of a dimension that is not only useful to classify, but also influential on other dimensions is platform structure. In this dimension, all cases are classified as either innovation platform or exchange platform. Moreover, when we observe the dimension key revenue stream, we can see that all innovation platforms use subscriptions and all except one exchange platforms (21st Real Estate as a special case) use commissions. Therefore, the dimension platform structure is not only helpful to classify the cases into different characteristics, but also influential on other dimensions.

We follow these steps for all dimensions and ultimately, we specify platform structure and platform participants as key differentiating dimensions of our final taxonomy as they are most suitable based on the abovementioned selection criteria. However, besides these key dimensions, our taxonomy also includes other dimensions that contribute to further differentiate classes of DPs.

Subsequently, we consider the different constellations of these two design dimensions' constituent characteristics to derive four archetypes of DPs. Then we analyze for each of the four archetypes how the characteristics of their corresponding dimensions differ among the example cases that instantiate the respective archetype. Based on this, we exclude the four dimensions key value proposition, interaction content, interaction type and price discovery from our final taxonomy since it is not possible to explain their characteristics by referring to their corresponding archetype. For instance, regarding the key value proposition, all cases focused on efficiency except Houzz as a special case (emotional/social value through community building). Adding such dimensions to our taxonomy would not increase its utility, as it would not be possible to explain the classification of the cases regarding these design dimensions. 


\subsection{Evaluation of the Taxonomy}

As a purposeful (designed) artifact, this taxonomy is subject to evaluation. Depending on the purpose of the taxonomy, different strategies may be appropriate [26]. For taxonomies, Nickerson et al. (2013) suggest applying specific criteria that are based on DSR literature. Accordingly, we evaluate the taxonomy in two principal ways: We verify the objective and the subjective ending conditions (see Chapter 3.2.).

Regarding the objective ending conditions, the dimensions of our taxonomy were selected in a way that they are not overlapping (mutually exclusive) but at the same time complement one another to provide a better explanation of the business models of DPs (collectively exhaustive).

Regarding the subjective ending conditions, we illustrate that the taxonomy can be considered concise, robust and explanatory by evaluating the taxonomy based on its purpose. As introduced above, the purpose of our taxonomy is to organize DP's diverse instances and conceptualizations into a coherent organizing structure from a business model perspective. We argue in two ways that this reduction in design decisions is a suitable choice even beyond the real estate industry. First, we collected the design dimensions from general and not industry-specific platforms and business ecosystems literature, which increases the generalizability of the taxonomy. Second, the two final design dimensions platform structure and platform participants are of generic nature and have a high influence on the other dimensions, which highlights their potential to describe different DP types. Moreover, to name an example, in the financial services industry and also from a business model perspective, we are able to observe comparable configurations of DPs that would fit our archetypes. For instance, a consumer exchange platform that focuses on payment processing for end consumers and provides detailed spending analysis, or a business innovation platform that facilitates open banking projects by enabling different business organizations to jointly create products and services over their platform, thereby facilitating innovation through value co-creation.

\section{Archetypes}

In this section, we present the four archetypes of DPs that can be identified when considering the two key differentiating dimensions of the final taxonomy as well as the other complementary dimensions (see Table 2). These archetypes demonstrate how the developed taxonomy can be used to distinguish DP types with respect to their business model. In the following, we describe each of the four archetypes with reference to their generic characteristics. In addition, we include one exemplary case from our case selection (see Chapter 3.5.) as an illustration of each archetype.

\subsection{Business Innovation Platform}

As innovation platforms, platforms of this archetype apply partner management as their key activity and therefore primarily enable collaboration between different actors in order to increase their overall time and cost efficiency. Revenue is generated with subscription models in the form of Software as a Service (SaaS) solutions. Since the abovementioned collaboration between industry actors create very specific needs, the users often do not benefit from more users on their own side and only indirect network effects emerge. Economies of scale are high because the SaaS solutions can easily be improved and provided to other clients.

Sablono is an example of a business innovation platform. During the execution of complex construction projects, it is often difficult to know the status of all deliverables and tasks being carried out. Sablono's software enables a better monitoring and management of such projects by connecting different business actors that are involved and each have their own (financial) interests (e.g. construction managers, architects, asset managers, or construction workers). Usually, there is a hierarchical structure between the actors on Sablono's platform as for each project there is one focal actor (e.g. the construction manager) that decides who gets access to which project data and who usually pays for the SaaS based on the desired features. Usually, the actors do not benefit from more actors in their own actor category (i.e. no direct network effects emerge). Sablono's software leads to horizontal but not to vertical integration as the actors are primarily from within the same industry.

\subsection{Consumer Innovation Platform}

Platforms of this archetype also focus on partner management as their key activity, since they foster collaboration among the user groups in order to improve efficiency which is similar to the business innovation platforms. In this archetype, however, there is a stronger focus on end users (in the case of real estate usually private individuals like tenants or buyers of furniture). These end users are a crucial element of consumer innovation platforms because their interaction ideally helps its orchestrator to attract business clients (e.g. service or insurance 
providers) to the platform. The platforms also capture most revenue with SaaS solutions (based on features or quantity) - but generally from the service providers and not from end users. There is a certain level of hierarchy between the platform participants because the paying platform user (usually a business client) can choose with whom (i.e. which partners) they wish to cooperate over the platform. Therefore, only end users can freely join the platform. Strong direct network effects often (but not in all cases) emerge in these platforms because the value for end users increases if more other end users (i.e. users on the same side) join the platform. Integration is vertical as consumer innovation platforms often allow external service providers from other industries to sell their services (e.g. insurance services for tenants).

Table 2. Four archetypes of digital platforms $s^{1,2,3}$

\begin{tabular}{lcccc}
\hline & $\begin{array}{c}\text { Business Innovation } \\
\text { Platform }\end{array}$ & $\begin{array}{c}\text { Consumer Innovation } \\
\text { Platform }\end{array}$ & $\begin{array}{c}\text { Business Exchange } \\
\text { Platform }\end{array}$ & $\begin{array}{c}\text { Consumer Exchange } \\
\text { Platform }\end{array}$ \\
\hline Platform participants & Business & Consumer & Business & Consumer \\
\hline Platform structure & Innovation & Innovation & Exchange & Exchange \\
\hline Key activity & Partner management & Partner management & Data services & Data services* \\
\hline Interface & Both & Both & Web-based* & Both \\
\hline Key revenue stream & Subscriptions & Subscriptions & Commissions* & Commissions \\
\hline Price discrimination & Feature & Feature* & None & None \\
\hline Coordination & Hierarchy & Hierarchy & Market & Market \\
\hline Accessibility & Restricted & Restricted & Open* & Open \\
\hline Interaction mode & Collaborative & Collaborative & Competitive & Collaborative \\
\hline Direct network effects & None & Strong* & Moderate & Strong \\
\hline Economies of scale & Strong & Strong & Moderate & Strong \\
\hline Integration & Horizontal & Vertical & Horizontal & Vertical* \\
\hline Exemplary cases & Sablono, Architrave, & Allthings, Flatfox & Wunderflats, 21st Real & Houzz, Exporo \\
\hline
\end{tabular}

Allthings is an example of a consumer innovation platform. In tenant management there was often a lack of transparent and efficient processes between property owners, property managers, service providers and tenants. Allthings' SaaS solution connects all these actors and enables a better communication over its platform. Property owners further benefit from lower operating costs and potentially also higher property values through the improved management. Similar to business exchange platforms, in the Allthings case there is also a hierarchical coordination by focal actors (property

\footnotetext{
${ }^{1}$ For the characteristics marked with an asterisk we identified a maximum of two different characteristics and chose the primary characteristic, i.e. the one that applies to the majority of cases (for archetypes with three cases) or the one that better fits the context of the archetype (for archetypes with two cases).

${ }^{2}$ We collected the data for these illustrations from the website of the respective cases as of September 2019.

3 As explained in Chapter 3.6., we excluded four design dimensions from the "preliminary version" of our taxonomy (Table 1) before we specify our final taxonomy. Due to this, these four dimensions are not used to describe the DP archetypes (Table 2) that are derived from our final taxonomy.
}

owners) that pay for their offerings based on desired features. There is also no competition between the actors involved, as the property owners usually work with partner firms when services need to be provided to tenants. An important difference to business innovation platforms is the focus on consumers (i.e. in this case tenants) that also benefit from high activity of other consumers as this allows them to e.g. borrow goods or share information in their buildings (i.e. direct network effects emerge).

\subsection{Business Exchange Platform}

As exchange platforms, platforms of this archetype facilitate exchanges between the different groups of actors and usually generate revenue by capturing commissions on the exchange that takes place using the platform. These platforms act as a marketplace, whereby the setting is less hierarchical compared to innovation platforms (i.e. there is no focal actor that decides who gets access to the platform as discussed for innovation platforms). However, platforms of this archetype exhibit different degrees of openness. While in some cases, 
all actors can access the platform, others only make it accessible for one side (usually buyers) and limit access for other sides (e.g. business clients/ service providers) that need to conduct an assessment in order to be granted access to the platform. Since sellers somehow benefit from an increasing number of other sellers as this ultimately increases the platform's attractiveness for buyers, moderate direct network effects emerge. Economies of scale are also moderate in this archetype because the overall number of actors on the platform is considerably lower than in a consumer platform as well due to the highly specialized exchange in the business environment that cannot be easily multiplied (e.g. a certain property sale may only be attractive for a small group of potential buyers due to extremely high investment volumes). Lastly, integration is mainly horizontal due to a limited focus on actors from other industries.

Wunderflats is an example of a business exchange platform. For employees who are temporarily in a new city, it is often not worth it to book a hotel as it is less practical and more expensive than having an apartment. However, searching the right apartment is a rather time-consuming task due to hidden costs in the mentioned price or a variety of different providers. Wunderflats provides a web-based platform that mediates high-quality, furnished apartments between companies (that search for accommodations for their employees) and landlords. Various data services and search functions make apartment search considerably easier. To win tenants, landlords compete against each other. In the case of successful transactions, Wunderflats charges a predetermined commission fee from buyers (i.e. guests). The platform is open for all potential users but landlords need to fulfill certain basic quality requirements.

\subsection{Consumer Exchange Platform}

Similar to the third archetype, consumer exchange platforms also provide data services to clients in order to increase efficiency. However, contrary to business exchange platforms, they add classical consumer-to-consumer $(\mathrm{C} 2 \mathrm{C})$ services and connect end consumers with other end consumers. Similar to business exchange platforms, revenue is primarily captured in the form of commissions on sales that are paid over the platform for the exchange. Sometimes consumer exchange platforms enhance communities in which the direct network effects are extremely strong. The platform setting is very open, collaborative and with almost no hierarchies. Every user and service provider can register and take part in the interaction. Economies of scale are high as the platform can pursue strong growth when the number of users in the different actor groups grow. Integration is often vertical when service providers from different industries are able to sell additional services (e.g. insurance providers).

Houzz is an example of a consumer exchange platform. When remodeling their home, people often have to walk their way through endless magazines for inspiration and it can be hard to find the right professionals for the implementation. Houzz is a leading platform for home remodeling, interior design and decorating and built a community around these topics. End-consumers can register on the platform and get suggestions for remodeling ideas from other end users or from professional service providers. These professionals sell their services on the platform and need to pay a commission fee on successful sales. Due to the strong community and sharing of ideas between end consumers, strong direct network effects emerge.

\section{Discussion and Conclusion}

We started with the premise that a better understanding and classification of the various business models of DPs requires the identification of their main design dimensions and characteristics. Following the approach of Nickerson et al. (2013) for taxonomy development in information systems research, our resulting taxonomy distinguishes DPs based on twelve design dimensions, of which two dimensions are fundamental, and their corresponding characteristics. We further differentiate four DP archetypes that are derived by combining the two fundamental design dimensions.

\subsection{Contributions}

First of all, we offer a coherent organizing structure of DPs from a business model perspective. This effort can be considered a step forward in clarifying and structuring DP types and configurations. Such endeavors are of both theoretical and practical value due to the still emergent, but highly relevant phenomenon of DPs and platform-based business ecosystems.

As a contribution to research, we reduce the initially outlined lack of conceptual clarity regarding the peculiarities of different platforms due to the variety in configurations and applications. In line with the main premise of taxonomies, we offer a structured representation of different DP types. 
Generally, given a high number of dimensions and characteristics, a DP can adopt a multitude of configurations. Empirically, however, we derived four distinct archetypes with twelve business model design dimensions and associated characteristics, thereby illustrating that successful platforms do not combine possible characteristics arbitrarily but focus on specific characteristics. The four archetypes illustrate how our taxonomy can be used to distinguish different DP types and help scholars in guiding and organizing the theorization of DPs and their designs.

For practitioners, our taxonomy highlights that not all platforms are equal and enables them to differentiate different platforms based on the dimensions and characteristics of their business model. This is beneficial for both platform designers and managers, either as an initial design guidance when launching a platform or as a context-dependent design guidance to identify possible adaptation variants once business model choices become necessary. Furthermore, we identified patterns regarding each of the four archetypes that can be used as specific guidance during the design and management of DPs. Finally, our dimensions provide a basis for platform benchmarking, as they allow the comparison of different platform types across various aspects of their business model (i.e. value creation, delivery and capture).

\subsection{Limitations}

This paper also faces some limitations. First, a limitation of detail and precision: Even though the relatively high number of cases [27] increases the comprehensiveness of the taxonomy, it potentially results in a too high-level analysis where some particularities of the cases are not taken into account. Second, a limitation of validity: Since we derived the key design dimensions based on their ability to classify the analyzed cases into archetypes, additional cases may be useful to validate the classification dimensions. Further, as suggested by Nickerson et al. (2013), conducting an empirical-to-conceptual (E2C) approach could provide additional insights on validity of our findings. Third, a limitation of context: While we are confident that our taxonomy is generic enough to be applied to different use cases, the examination of the taxonomy's dimensions and characteristics were only informed by cases from real estate industry. Fourth, a limitation of the time dimension: Even if the dimensions remain relevant for DPs, the individual characteristics of each analyzed case might change over time because of evolving governance preferences of DP owners.

\subsection{Future Research}

Next to overcoming the abovementioned limitations, we encourage prospective research to also link DP configurations to performance in certain contexts. While we provided four archetypes of DPs from a business model perspective, we did not link these archetypes to the outcomes of these configurations. We encourage future research to apply our taxonomy to generate insights on systematic, configuration-dependent DP performance differences.

\section{Acknowledgements}

This work has been supported by the Swiss National Science Foundation (SNSF).

\section{References}

[1] K. Täuscher and S. M. Laudien, "Understanding platform business models: A mixed methods study of marketplaces", European Management Journal, vol. 36, no. 3, 2018, pp. 319329.

[2] A. Tiwana, Platform Ecosystems: Aligning Architecture, Governance, and Strategy, Morgan Kaufmann, Amsterdam, 2014.

[3] G. Parker, M. Van Alstyne, and X. Y. Jiang, "Platform Ecosystems: How Developers Invert the Firm", MIS Quarterly, vol. 41, no. 1, 2017, pp. 255-266.

[4] M. G. Jacobides, C. Cennamo, and A. Gawer, "Towards a theory of ecosystems", Strategic Management Journal, vol. 39, no. 8,2018 , pp. 2255-2276.

[5] M. de Reuver, C. Sørensen, and R. C. Basole, "The Digital Platform: A Research Agenda", Journal of Information Technology, vol. 33, no. 2, 2018, pp. 124-135.

[6] M. M. Al-Debei and D. E. Avison, "Developing a unified framework of the business model concept", European Journal of Information Systems, vol. 19, 2010, pp. 359-376.

[7] M. Smith, "The Gartner Business Value Model: A Framework for Measuring Business Performance," Gartner, Stamford, 2010.

[8] D. J. Teece, "Business models, business strategy and innovation", Long range planning, vol. 43, no. 2, 2010, pp. 172-194.

[9] R. C. Nickerson, U. Varshney, and J. Muntermann, "A Method for Taxonomy Development and its Application in Information Systems", European Journal of Information Systems, vol. 22, no. 3, 2013, pp. 336-359.

[10] A. Gawer, "Bridging differing perspectives on technological platforms: Toward an integrative framework", Research Policy, vol. 43, no. 7, 2014, pp. 1239-1249.

[11] T. Eisenmann, G. Parker, and M. W. V. Alstyne, "Strategies for Two-sided Markets", Harvard Business Review, vol. 84, 2006, pp. 92-101.

[12] M. L. Katz and C. Shapiro, "Systems Competition and Network Effects", Journal of Economic Perspectives, vol. 8, no. 2, 1994, pp. 93-115. 
[13] C. Y. Baldwin and C. J. Woodard, "The Architecture of Platforms: A Unified View", in Platforms, Markets and Innovation, A. Gawer Ed., Edward Elgar Publishing, London, 2009, pp. 19-44

[14] A. Tiwana, B. Konsynski, and A. A. Bush, "Platform Evolution: Coevolution of Platform Architecture, Governance, and Environmental Dynamics", Information Systems Research, vol. 21, no. 4, 2010, pp. 675-687.

[15] A. Ghazawneh and O. Henfridsson, "Balancing platform control and external contribution in third-party development: the boundary resources model", Information Systems Journal, vol. 23, no. 2, 2013, pp. 173-192.

[16] J. F. Moore, The Death of Competition: Leadership and Strategy in the Age of Business Ecosystems, Harper Business, New York, 1996.

[17] R. Adner, "Match Your Innovation Strategy to Your Innovation Ecosystem", Harvard Business Review, vol. 84, no. 4, 2006, pp. 98-107.

[18] R. Adner, "Ecosystem as Structure: An Actionable Construct for Strategy", Journal of Management, vol. 43, no. 1, 2017, pp. 39-58.

[19] C. Zott, R. Amit, and L. Massa, "The business model: Recent developments and future research", Journal of Management, vol. 37, no. 4, 2011, pp. 1019-1042.

[20] O. Gassmann, K. Frankenberger, and M. Csik, The Business Model Navigator: 55 Models That Will Revolutionise Your Business, Pearson Education Limited, Harlow, 2014.

[21] S. T. March and G. F. Smith, "Design and Natural Science Research on Information Technology", Decision Support Systems, vol. 15, no. 4, 1995, pp. 251-266.

[22] K. Peffers, T. Tuunanen, M. Rothenberger, and S. Chatterjee, "A Design Science Research Methodology for Information Systems Research", Journal of Management Information Systems, vol. 24, no. 3, 2007, pp. 45-77.

[23] M. Siering, B. Clapham, O. Engel, and P. Gomber, "A taxonomy of financial market manipulations: establishing trust and market integrity in the financialized economy through automated fraud detection", Journal of Information Technology, vol. 32, no. 3, 2017, pp. 251-269.

[24] N. Prat, I. Comyn-Wattiau, and J. Akoka, "A Taxonomy of Evaluation Methods for Information Systems Artifacts", Journal of Management Information Systems, vol. 32, no. 3, 2015, pp. 229-267.
[25] blackprintpartners, PropTech Yearbook 2018, blackprintpartners, Frankfurt am Main, 2018.

[26] J. R. Venable, J. Pries-Heje, and R. Baskerville, "FEDS: a Framework for Evaluation in Design Science Research", European Journal of Information Systems, vol. 25, no. 1, 2016, pp. 77-89.

[27] K. M. Eisenhardt, "Building Theories from Case-Study Research", Academy of Management Review, vol. 14, no. 4, 1989, pp. 532-550.

[28] S. P. Choudary, G. G. Parker, and M. Van Alstyne, Platform Scale: How an Emerging Business Model Helps Startups Build Large Empires with Minimum Investment, Platform Thinking Labs, S.L., 2015.

[29] A. Gawer, Platforms, Markets, and Innovation, Edward Elgar, Cheltenham, Gloucestershire, UK, 2009.

[30] B. W. Wirtz, Business Model Management: Design Instruments - Success factors (2nd ed.), Springer Fachmedien, Wiesbaden, 2015.

[31] B. Tan, S. L. Pan, X. H. Lu, and L. H. Huang, "The Role of IS Capabilities in the Development of Multi-Sided Platforms: The Digital Ecosystem Strategy of Alibaba.com", Journal of the Association for Information Systems, vol. 16, no. 4, 2015, pp. 248-280.

[32] Y. Bakos, "The Emerging Role of Electronic Marketplaces on the Internet", Communications of the ACM, vol. 41, no. 8, 1998, pp. 35-42.

[33] A. Osterwalder, "The business model ontology: A proposition in a design science approach," Dissertation, University of Lausanne, 2004.

[34] M. Iansiti and R. Levien, The Keystone Advantage: What the New Dynamics of Business Ecosystems Mean for Strategy, Innovation, and Sustainability, Harvard Business Press, Boston, 2004, p. 278.

[35] K. J. Boudreau and K. R. Lakhani, "How to Manage Outside Innovation", MIT Sloan Management Review, vol. 50, no. 4, 2009, pp. 69-76.

[36] Q. Dai and R. J. Kauffman, "Business Models for Internetbased E-Procurement Systems and B2B Electronic Markets: An Exploratory Assessment," in Proceedings of the 34th Hawaii International Conference on System Sciences, Maui, Hawaii, 2001, p. 158.

\section{Appendix}

Table 3. Overview of business model categories and design dimension candidates

\begin{tabular}{|c|c|c|c|}
\hline Category & Design dimension & Descriptions & Refs. \\
\hline \multirow[t]{7}{*}{$\begin{array}{l}\text { Value } \\
\text { Proposition }\end{array}$} & & $\begin{array}{l}\text { The value that is delivered to a customer, including the products and services as well as the } \\
\text { customer problems that are being solved. }\end{array}$ & {$[20]$} \\
\hline & Key activity & The platform's primary activity that delivers the value proposition to customers. & {$[28]$} \\
\hline & $\begin{array}{l}\text { Key value } \\
\text { proposition }\end{array}$ & The main benefit that the platform delivers to the customer. & {$[1,20]$} \\
\hline & Platform structure & $\begin{array}{l}\text { The platform's structure either as innovation platform that facilitates collaboration between } \\
\text { customer groups or as exchange platform that promotes transactions between them. }\end{array}$ & [29] \\
\hline & Interface & $\begin{array}{l}\text { Refers to whether the platform primarily interacts with its customers through a mobile } \\
\text { application, a web-based version or both channels. }\end{array}$ & [2] \\
\hline & Interaction content & Refers to whether a product/ service is the basis for interaction on the platform. & [30] \\
\hline & Interaction type & Refers to whether the interaction on the platform happens digitally or offline. & {$[30]$} \\
\hline \multirow[t]{2}{*}{$\begin{array}{l}\text { Target } \\
\text { Customer }\end{array}$} & & $\begin{array}{l}\text { Refers to choices regarding the customer segments, customer relationships, and distribution } \\
\text { channels. }\end{array}$ & [20] \\
\hline & $\begin{array}{l}\text { Platform } \\
\text { participants }\end{array}$ & The type of customer segments that the platform primarily connects as platform participants. & [31] \\
\hline
\end{tabular}




\begin{tabular}{|c|c|c|c|}
\hline \multirow[t]{4}{*}{$\begin{array}{l}\text { Revenue } \\
\text { Model }\end{array}$} & & $\begin{array}{l}\text { Refers to how much and why the customers will pay, from what sources the income is } \\
\text { generated as well as the major cost drivers and financial risks. }\end{array}$ & {$[20]$} \\
\hline & $\begin{array}{l}\text { Key revenue } \\
\text { stream }\end{array}$ & The platform's primary source of revenue. & {$[2]$} \\
\hline & Price discovery & $\begin{array}{l}\text { Refers to the price determination, i.e. by interference of a focal actor (i.e. orchestrator) or via a } \\
\text { free market. }\end{array}$ & {$[32]$} \\
\hline & $\begin{array}{l}\text { Price } \\
\text { discrimination }\end{array}$ & Refers to whether the platform adjusts prices for different platform participants. & {$[2,33]$} \\
\hline \multirow[t]{7}{*}{$\begin{array}{l}\text { Value } \\
\text { Chain }\end{array}$} & & $\begin{array}{l}\text { Refers to what key resources are behind the value proposition, what core competencies are } \\
\text { needed, who the most important suppliers/ partners are and what they can contribute. }\end{array}$ & {$[20]$} \\
\hline & Coordination & $\begin{array}{l}\text { Refers to whether the platform is coordinated by a focal actor (i.e. orchestrator) or if there is a } \\
\text { market where the platform participants independently negotiate (e.g. regarding the price). }\end{array}$ & [34] \\
\hline & Accessibility & $\begin{array}{l}\text { Refers to the platform's openness, i.e. whether it is accessible to all potential platform } \\
\text { participants, open with restrictions or closed. }\end{array}$ & {$[10]$} \\
\hline & Interaction mode & Refers to whether the platform promotes collaborative communities or competitive markets. & {$[35]$} \\
\hline & $\begin{array}{l}\text { Direct network } \\
\text { effects }\end{array}$ & $\begin{array}{l}\text { Refers to whether the value for one group of platform participants increases with an } \\
\text { increasing number of users (i.e. increased participation) in their own participants group. }\end{array}$ & $\begin{array}{l}{[10,} \\
11]\end{array}$ \\
\hline & Economies of scale & $\begin{array}{l}\text { The platform's ability to generate Economies of scale, i.e. whether they can easily expand } \\
\text { their base of platform participants with their existing offering. }\end{array}$ & {$[2]$} \\
\hline & Integration & $\begin{array}{l}\text { Refers to whether the platform supports horizontal (same industry) or vertical (other industry) } \\
\text { market integration. }\end{array}$ & [36] \\
\hline
\end{tabular}

Table 4. Application of design dimensions to digital platform cases

\begin{tabular}{|c|c|c|c|c|c|}
\hline & Immorocks & Architrave & Exporo & $\begin{array}{c}\text { Service Partner } \\
\text { ONE }\end{array}$ & Houzz Germany \\
\hline Key activity & Data & Partner & Data & Partner & Community \\
\hline Key value proposition & Efficiency & Efficiency & Efficiency & Efficiency & Emotional \\
\hline Platform structure & Exchange & Innovation & Exchange & Innovation & Exchange \\
\hline Interface & Web-based & Both & Both & Both & Both \\
\hline Interaction content & Product & Service & Product & Service & Service \\
\hline Interaction type & Digital & Offline & Digital & Offline & Digital \\
\hline Platform participants & Business & Business & Consumer & Business & Consumer \\
\hline Key revenue stream & Commissions & Subscriptions & Commissions & Subscriptions & Commissions \\
\hline Price discovery & Market & Orchestrator & Orchestrator & Orchestrator & Orchestrator \\
\hline Price discrimination & None & Feature & None & Feature & None \\
\hline Coordination & Market & Hierarchy & Market & Hierarchy & Market \\
\hline Accessibility & Restricted & Restricted & Open & Restricted & Open \\
\hline Interaction mode & Competitive & Collaborative & Collaborative & Collaborative & Collaborative \\
\hline Direct network effects & None & None & None & None & Strong \\
\hline Economies of scale & Moderate & Strong & Strong & Strong & Strong \\
\hline \multirow[t]{2}{*}{ Integration } & Horizontal & Horizontal & Horizontal & Horizontal & Vertical \\
\hline & Wunderflats & 21st Real Estate & Sablono & Allthings & Flatfox \\
\hline Key activity & Data & Data & Partner & Partner & Partner \\
\hline Key value proposition & Efficiency & Efficiency & Efficiency & Efficiency & Efficiency \\
\hline Platform structure & Exchange & Exchange & Innovation & Innovation & Innovation \\
\hline Interface & Web-based & Web-based & Both & Both & Both \\
\hline Interaction content & Service & Service & Service & Service & Service \\
\hline Interaction type & Offline & Offline & Offline & Offline & Offline \\
\hline Platform participants & Business & Business & Business & Consumer & Consumer \\
\hline Key revenue stream & Commissions & Subscriptions & Subscriptions & Subscriptions & Subscriptions \\
\hline Price discovery & Orchestrator & Orchestrator & Orchestrator & Orchestrator & Orchestrator \\
\hline Price discrimination & None & None & Feature & Feature & Quantity \\
\hline Coordination & Market & Market & Hierarchy & Hierarchy & Hierarchy \\
\hline Accessibility & Open & Open & Restricted & Restricted & Restricted \\
\hline Interaction mode & Competitive & Competitive & Collaborative & Collaborative & Collaborative \\
\hline Direct network effects & None & None & None & Strong & None \\
\hline Economies of scale & Moderate & Moderate & Strong & Strong & Strong \\
\hline Integration & Horizontal & Horizontal & Horizontal & Vertical & Vertical \\
\hline
\end{tabular}

